\title{
PERANCANGAN BOARD GAME EDUKATIF UNTUK KELUARGA
}

\author{
Yolanda Chandra, \\ Benny Rahmawan Noviadji, \\ Arjuna Bangsawan.
Institut Informatika Indonesia (IKADO), Surabaya. mepurplegirl1807@gmail.com

\begin{abstract}
Abstrak
Seiring dengan perkembangan zaman dan teknologi, banyak terjadi perubahan budaya dan gaya hidup di masyarakat. Zaman modern saat ini, jarang sekali orang tua menghabiskan waktu bersama keluarga dan mulai tidak mengawasi permainan yang dimainkan oleh anak-anak mereka. Oleh sebab itu diperlukan media permainan untuk keluarga yang bertujuan mempererat hubungan antar keluarga. Board game menjadi salah satu alternatif permainan yang sangat digemari oleh anak-anak dan memberikan nilai-nilai edukasi di dalamnya. Perancangan Board Game Edukatif untuk Keluarga ini bertujuan agar anak-anak tidak bermain secara individual, mengenalkan kembali board game yang mulai dilupakan dan ditinggalkan oleh keluarga dan dapat memberantas tema-tema permainan yang mulai tidak mendidik. Metode pengumpulan data dibagi menjadi dua yaitu metode pengumpulan data primer dan sekunder. Metode pengumpulan data primer dilakukan dengan melakukan wawancara mendalam terhadap beberapa keluarga, para narasumber yang berkaitan dan kuesioner. Sedangkan metode pengumpulan data sekunder dengan melakukan observasi dengan beberapa keluarga, kepustakaan dan data yang terdapat di internet. Board Game yang memiliki tema nusantara ini dirancang menggunakan gaya visual kartun serta menampilkan keanekaragaman nusantara yang terdapat di Indonesia. Dengan adanya perancangan ini diharapkan board game menjadi salah satu media permainan yang layak dan dapat dimainkan bersama dengan keluarga.
\end{abstract}

Kata kunci: Desain interaktif, Keluarga, Edukasi, Nusantara..

\begin{abstract}
Along with the times and technology, many changes of culture and lifestyle in the community. In modern times, rarely parents spend time with their family and they start not watching the game as it is played by their children. Therefore, needs necessary media play to a family that aims to strengthen the relationship between the family. Board games became one of alternative games are very popular with children and provide educational value on it. Designing Educational Board Game for the Family so that children do not play individually,
\end{abstract}


board games reintroduce forgotten dan abandoned by the family and can eradicate the theme of the game is started do not educate. Methods of data collection is divided into two: the method of collecting primary and secondary data. Methods of collecting primary data done by depht interview with some families, the sources related and questionnaires. While secondary data collection methods by observation with some families, literature, and the data contained on the internet.Board game have been designed using the theme archipelago, cartoon visual style and show the diversity contained in the Indonesian archipelago. With the design of the game board is expected to become one of the media decent game and can be played together with the family.

Keywords: Interactive Design, Family, Education, Archipelago.

\section{PENDAHULUAN}

Seiring perkembangan zaman dan teknologi membuat permainan ikut berkembang serta memiliki berbagai macam jenis dan bentuk, mulai dari bentuk fisik hingga digital yang dapat dimainkan oleh satu orang saja atau beberapa orang sekaligus. Seperti yang kita ketahui permainan digunakan sebagai media untuk mengajarkan kerja sama, persahabatan, kontrol perilaku, mengenalkan normanorma dan juga digunakan untuk melatih emosi agar sabar serta tidak cepat marah. Permainan juga dapat dilakukan untuk rekreasi dan mengisi waktu luang. Bermain salah satu cara yang paling tepat untuk mengembangkan kemampuan anak sesuai kompetensinya. Melalui bermain, anak memperoleh dan memproses informasi mengenai hal-hal baru dan berlatih melalui keterampilan yang ada.

Mulyadi (2014) menjelaskan bahwa anak adalah anak, anak senang sekali belajar dan bermain, karena itu metode pembelajarannya harus disesuaikan dengan cara-cara bermain yang menyenangkan. Anak-anak senantiasa tumbuh dan berkembang, mereka menampilkan ciri-ciri fisik dan psikologis yang berbeda untuk tiap tahap perkembangannya. Pendidikan di rumah yang menekankan bermain sambil belajar dapat mendorong anak untuk mengeluarkan semua daya kreativitasnya. Seluruh potensi kecerdasan anak akan berkembang optimal apabila disirami suasana penuh kasih sayang dan jauh dari berbagai tindak kekerasan, sehingga anak-anak dapat bermain dengan gembira. Kegiatan belajar yang efektif 
pada anak dilakukan melalui cara-cara bermain aktif yang menyenangkan dan interaksi yang mengutamakan sentuhan emosional, bukan teori akademik.

Zaman modern saat ini, jarang sekali orang tua menghabiskan waktu bersama keluarga terutama anak-anak mereka. Dalam pengumpulan data terhadap beberapa keluarga menjelaskan bahwa anak-anak lebih banyak menghabiskan waktu bermainnya dengan teman daripada keluarga. Sebuah studi menunjukkan bahwa bermain video game bertema kekerasan dalam waktu panjang bisa menghambat "kedewasaan moral" remaja. Penelitian mendalam terhadap perilaku 100 remaja berusia 13-14 tahun menemukan bahwa bermain game bertema kekerasan secara berlebihan dapat menyebabkan si remaja kurang empati terhadap orang lain. Di antara remaja tersebut, lebih dari setengahnya bermain game komputer setiap hari dan game yang kerap dimainkan adalah permainan komputer yang mengandung kekerasan.

Oleh sebab itu, diperlukan media permainan untuk keluarga yang bertujuan mempererat hubungan antar anggota keluarga. Penulis berusaha merancang sebuah media permainan yang menghibur, unik dan mendidik. Board game menjadi salah satu alternatif permainan yang sangat digemari masyarakat khususnya anak-anak. Board game bukan hanya menyenangkan ketika dimainkan, melainkan juga memberikan nilai-nilai edukasi yang baik bagi yang memainkannya.

Hasil wawancara mendalam dengan beberapa keluarga dan observasi serta kesimpulan, penulis berhasil mendapatkan beberapa permasalahan yang timbul, berikut permasalahan yang ada: Anak-anak cenderung lebih bermain secara individu. Permainan board game yang kurang dikenal baik oleh keluarga di Indonesia. Tema permainan yang mulai tidak mendidik. Berdasarkan latar belakang di atas, maka peneliti merancang sebuah media edukatif berjudul "Perancangan board game edukatif untuk keluarga". Tujuan Perancangan media ini meliputi: a) Merancang board game edukatif sebagai media permainan yang menarik dan inovatif untuk mendekatkan keluarga; b) Merancang sebuah permainan yang bisa mendidik dan menambah wawasan pada keluarga khususnya anak-anak. 


\section{KAJIAN TEORI}

\section{Teori Permainan}

Permainan menurut Ismail (2006) terdapat dua pengertian. Pertama, permainan adalah sebuah aktivitas bermain yang murni mencari kesenangan tanpa mencari menang atau kalah. Kedua, permainan diartikan sebagai aktivitas bermain yang dilakukan dalam rangka mencari kesenangan dan kepuasan, namun ditandai pencarian menang-kalah. Singer dalam Kusatanti (2004) mengemukakan bahwa bermain dapat digunakan anak-anak untuk menjelajahi dunianya, mengembangkan kompetensi dalam usaha mengatasi dunianya dan mengembangkan kreativitas anak, dengan bermain anak memiliki kemampuan untuk memahami konsep secara ilmiah tanpa paksaan. Selanjutnya bermain menurut Mulyadi (2004) secara umum sering dikaitkan dengan kegatan anak-anak yang dilakukan secara spontan. Terdapat lima pengertian bermain yaitu pertama adalah sesuatu yang menyenangkan dan memiliki nilai intrinsik pada anak. Kedua, bermain tidak memiliki tujuan ekstrinsik, motivasi, lebih bersifat intrinsik. Ketiga, bermain bersifat spontan dan sukarela, tidak ada unsur keterpaksaan dan bebas dipilih oleh anak. Keempat, bermain melibatkan peran aktif keikutsertaaan anak. Terakhir, bermain memiliki hubungan sistematik yang khusus dengan sesuatu yang bukan bermain, seperti kreativitas, pemecahan masalah, belajar bahasa, perkembangan sosial dan sebagainya.

\section{Teori Board Game}

Board game menurut Scorviano dalam Mubarak (2013) adalah jenis permainan dimana alat-alat atau bagian-bagian permainan ditempatkan, dipindahkan atau digerakkan pada permukaan yang telah ditandai atau dibagi-bagi menurut perangkat aturan. Board game bukan merupakan hal yang asing atau baru bagi sebagian besar masyarakat Indonesia. Sebagai contoh catur, monopoli dan ular tangga merupakan board game yang sangat popular bagi masyarakat Indonesia khususnya bagi para penggemar game atau permainan.

Keberadaan board game tidak hanya menjadi alat sebagai penyalur hobi dan kegemaran bagi para penggemarnya, tetapi keberadaan board game juga dapat dimanfaatkan sebagai media edukasi bagi para penggunanya yang dirancang melalui berbagai macam tema. Monopoli salah satunya, board game dengan tema 
ekonomi dan bisnis merupakan jenis board game yang memberikan edukasi bagi para penggunanya untuk mengenal dan memahami dunia bisnis secara sederhana. Board game merupakan permainan yang penuh aturan, permainan board game akan berjalan dengan baik jika semua pemain mengikuti aturan yang telah dibuat permainan tersebut. Dengan demikian secara tidak langsung para pemain diajarkan untuk melatih kedisiplinan.

\section{METODE PENELITIAN}

Data penelitian diperoleh dari berbagai narasumber yang dapat mendukung untuk proses perancangan. Pencarian data dilakukan melalui metode sebagai berikut: a) Mengidentifikasi Fenomena dan Permasalahan; b) Studi kompetitor serta komparator. Studi kompetitor dilakukan terhadap permainan monopoli dan permainan ular tangga. Studi komparator dilakukan terhadap permainan The Game of Life, Scrabble dan The 3-D Smurf Game; c) Hasil wawancara dengan beberapa keluarga, toko mainan dan psikolog; d) Studi Literatur dan teori yang berhubungan dengan penelitian; c) Hasil dari polling dan kuesioner untuk mengetahui keinginan audiens serta menemukan permasalahan.

\section{HASIL DAN PEMBAHASAN}

\section{Proses Desain}

Proses desain board game dimulai dengan menentukan nama dari permainan tersebut. Nama atau logo yang didapat adalah JENTARA atau Jendela Nusantara yang memiliki arti sebagai pengetahuan yang terbuka seperti jendela yang terbuka lebar dan nusantara yang mewakilkan kepulauan Indonesia dari Sumatera hingga Papua. Logo dibuat dengan penggabungan logotype dan logogram dengan menggunakan teknik gestalt.

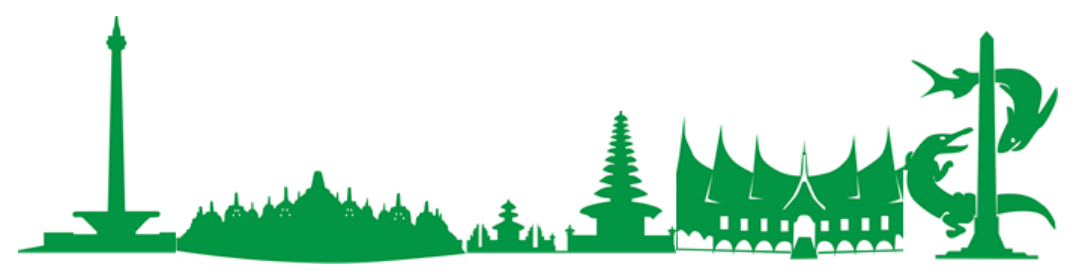

Gambar 1. Logo JENTARA.

Sumber: Dokumentasi penulis 

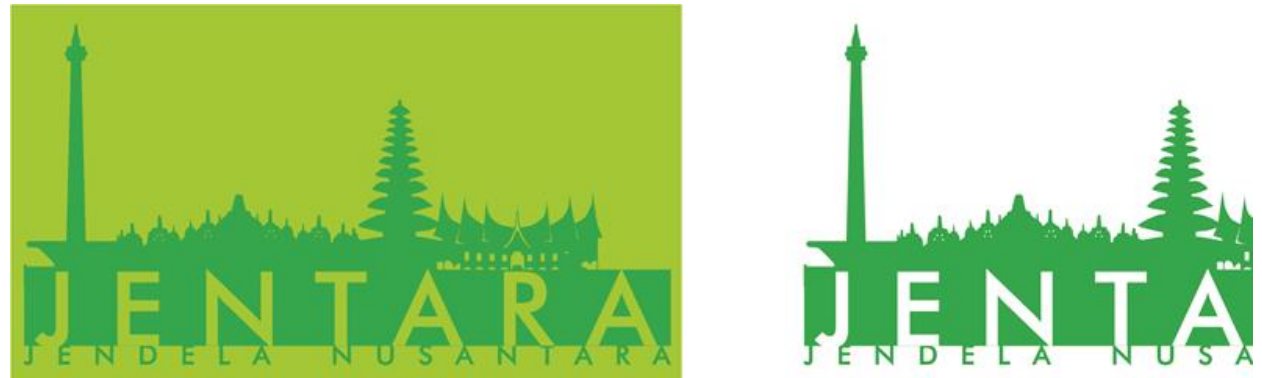

Gambar 2. Logo JENTARA

yang menggabungkan logogram dan logotype

Sumber: Dokumentasi Penulis

Selain logo, ada motif grafis yang dirancang guna sebagai pengganti logo JENTARA, motif grafis diambil dari kata menjelajah yang identik dengan kompas. Motif grafis sendiri digunakan pada kartu pos dan juga alur JELAJAH pada papan permainan.
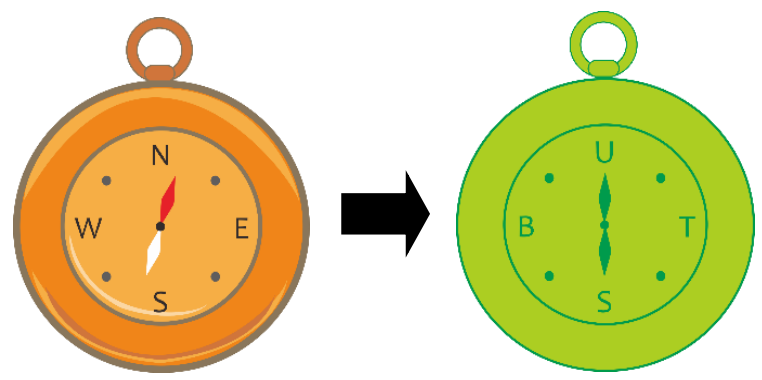

Gambar 3. Motif grafis yang telah disederhanakan Sumber: Dokumentasi Penulis

Desain papan permainan JENTARA berlatarbelakang kepulauan Indonesia dan digabungkan dengan 50 alur yang telah dilakukan penyederhanaan agar mudah dilihat dan tidak rumit.
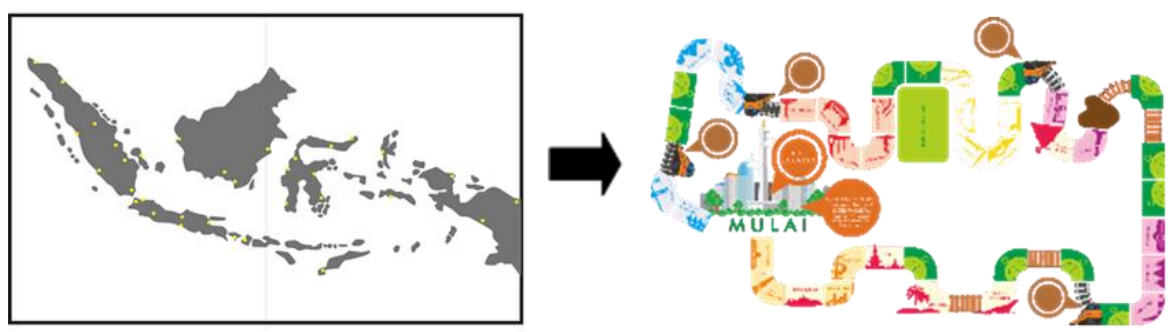

Gambar 4. Latar kepulauan Indonesia (foto kiri) dan alur (foto kanan)

Sumber: Dokumentasi penulis 
Pion/bidak yang ada dirancang dari 4 karakter anak-anak yang mewakili masyarakat, ras serta suku yang terdapat di Indonesia, dengan 2 anak perempuan dan 2 anak lelaki yang memilki warna kulit dan dari suku yang berbeda. Nama yang diambil dari abjad $\mathrm{ABCD}$ yang juga menggunakan nama umum orang Indonesia yaitu Agus, Budi, Cici dan Deta

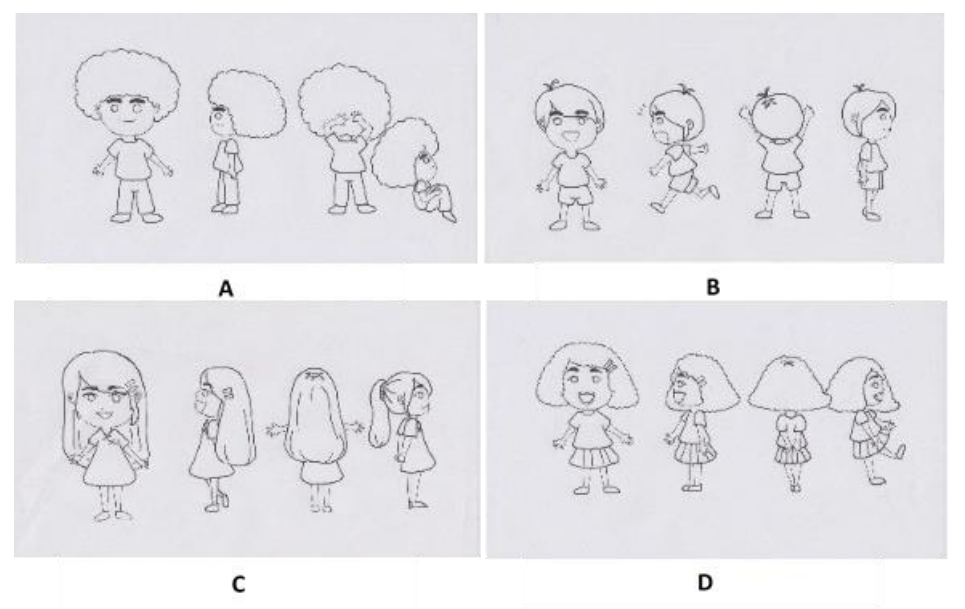

Gambar 5. Karakter anak-anak A) Agus; B) Budi;

C) Cici; D) Deta

Sumber: Dokumentasi penulis

Desain kartu pos kota/wisata dan kartu jelajah memiliki pengetahuan di dalamnya, mulai dari kota-kota yang terdapat di Indonesia hingga pengetahuan umum seperti budaya, kuliner dan tempat-tempat wisata.

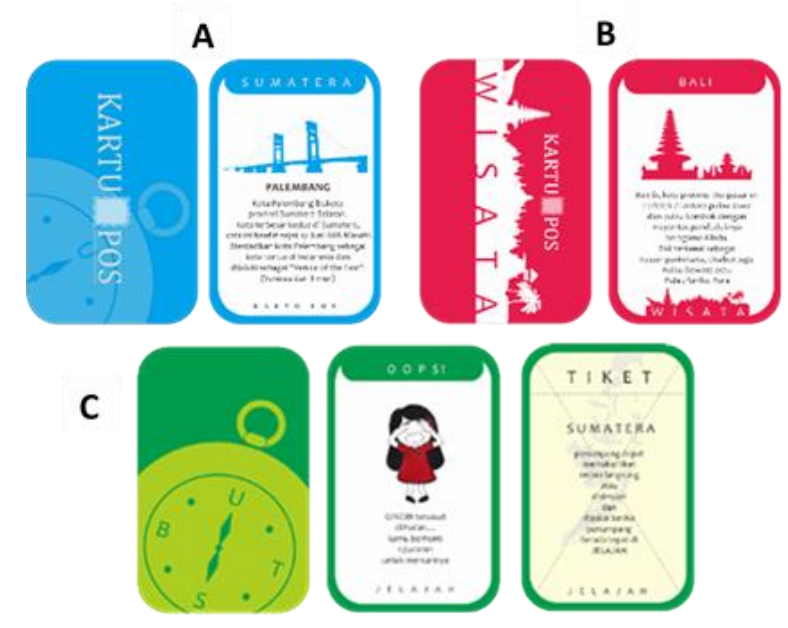

Gambar 6. A) Kartu pos kota; B) Kartu pos wisata; C) Kartu Jelajah Sumber: Dokumentasi penulis 


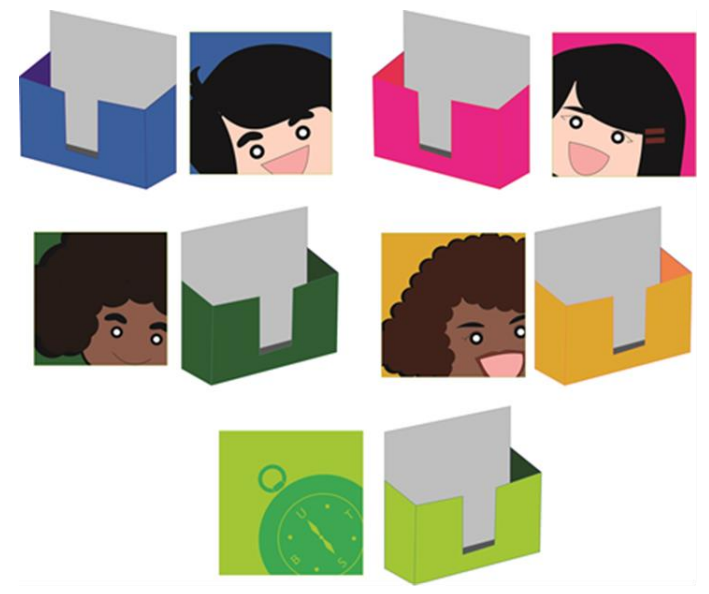

Gambar 7. Tempat kartu

Sumber: Dokumentasi penulis

Permainan JENTARA sendiri merupakan permainan yang menjelajahi Indonesia serta mengumpulkan kartu pos kota/wisata untuk bisa menjadi pemenang pada permainan JENTARA. Dengan menempuh berbagai alur kota dan mengumpulkan kartu pos yang berisi pengetahuan tersebut menjadi bukti bahwa para pemain telah berhasil menjelajahi Indonesia. Permainan dan peraturan yang ada telah tercantum dan dijelaskan secara lengkap pada buku panduan JENTARA.

\section{Desain Akhir}

Berikut adalah foto/gambar dari desain akhir media utama hingga media pendukung JENTARA

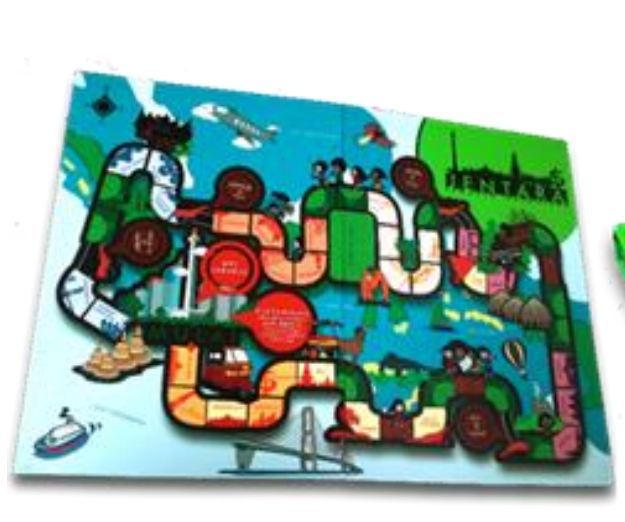

A

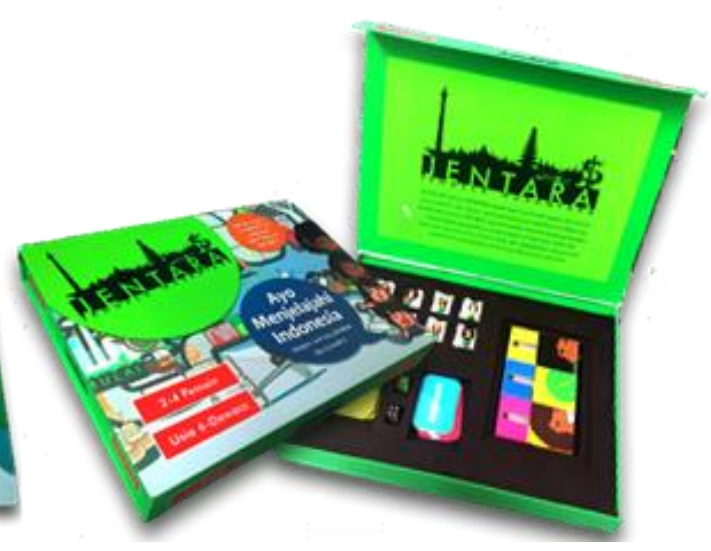

B

Gambar 8. A) Desain akhir papan permaina,

B) Desain akhir kemasan JENTARA

Sumber: Dokumentasi Penulis 

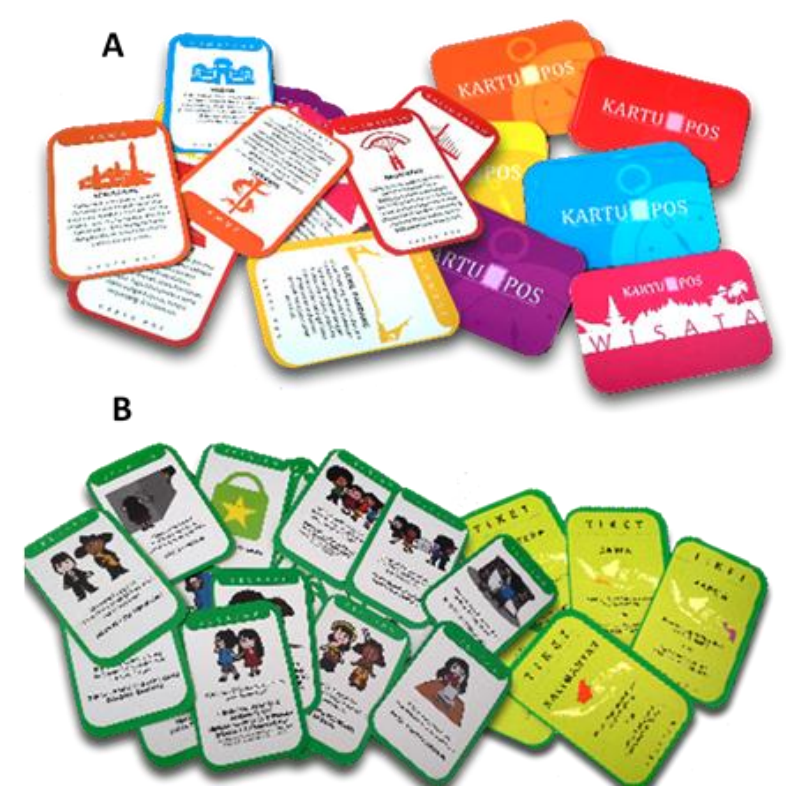

Gambar 9. A) Desain akhir kartu pos kota/wisata B) Desain akhir kartu jelajah Sumber: Dokumentasi penulis

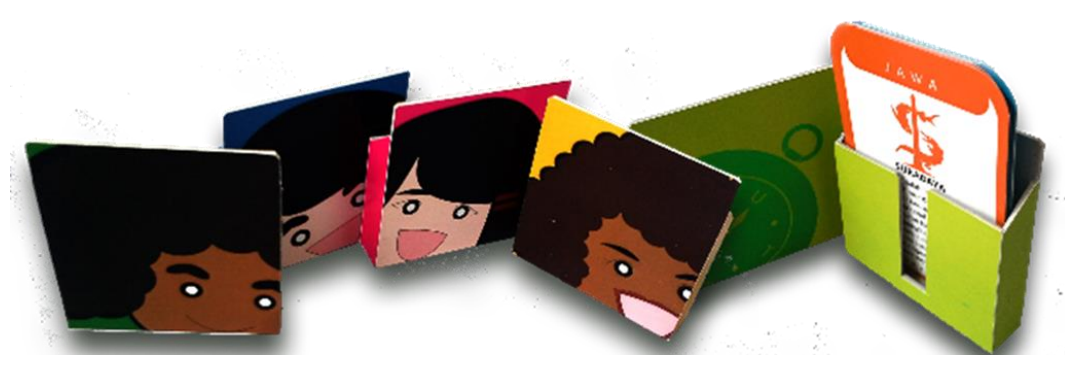

Gambar10. A) Desain akhir kartu pos kota/wisata

B) Desain akhir kartu jelajah Sumber: Dokumentasi penulis

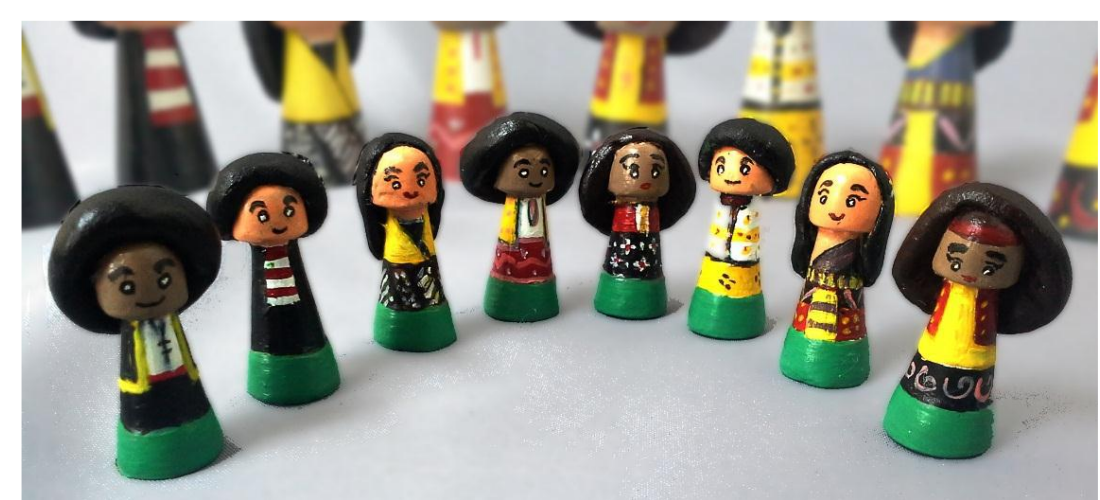

Gambar 11. Desain akhir pion/bidak

Sumber: Dokumentasi penulis 


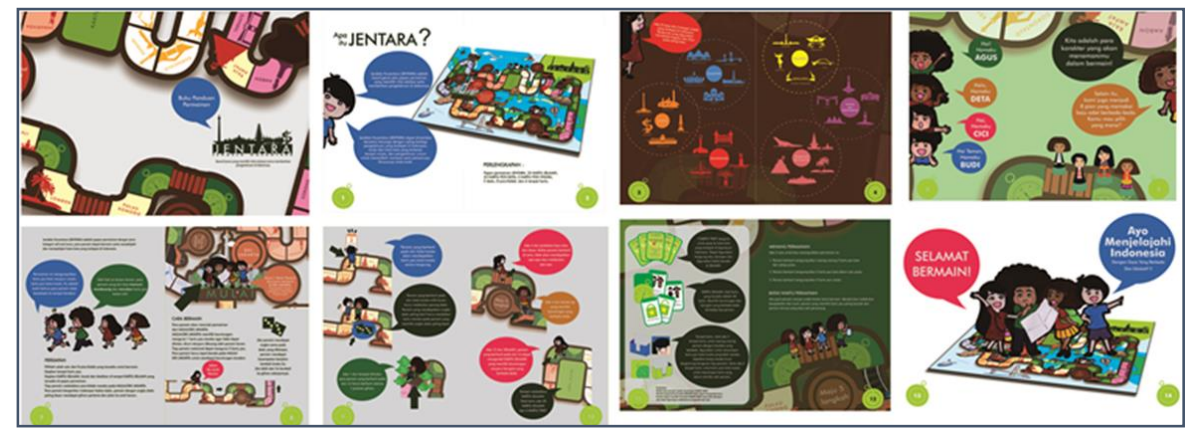

Gambar 12. Desain akhir/isi halaman buku panduan Sumber: Dokumentasi penulis

\section{Media pendukung}

Media pendukung dirancang bertujuan untuk mendukung dan menambahkan nilai lebih pada permainan JENTARA, seperti memberikan gantungan kunci dan kartu pos JENTARA lalu beberapa media promosi guna melancarkan distribusi serta mempromosikan JENTARA secara luas.

Media promosi yang dirancang adalah gantungan kunci, brosur, poster, flag chain, x-banner dan kaos.

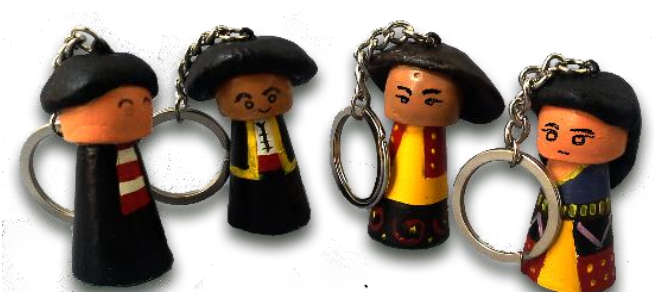

Gambar 13. Desain akhir gantungan kunci JENTARA Sumber: Dokumentasi penulis
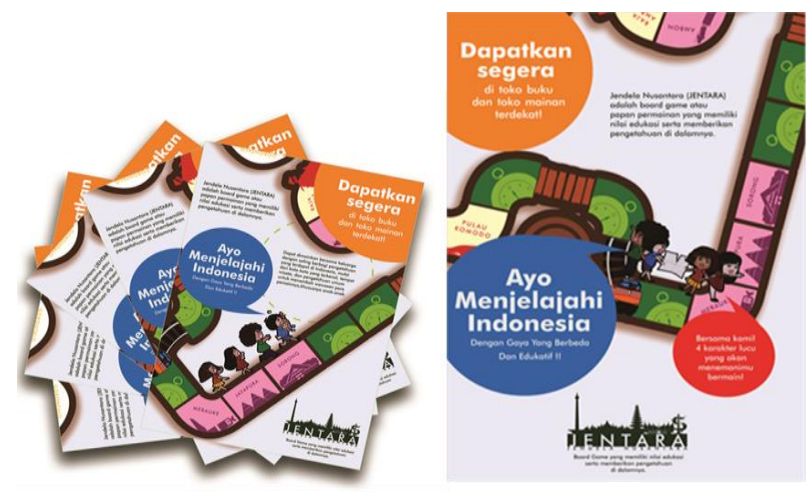

Gambar 14. Desain akhir brosur dan poster JENTARA Sumber: Dokumentasi penulis 

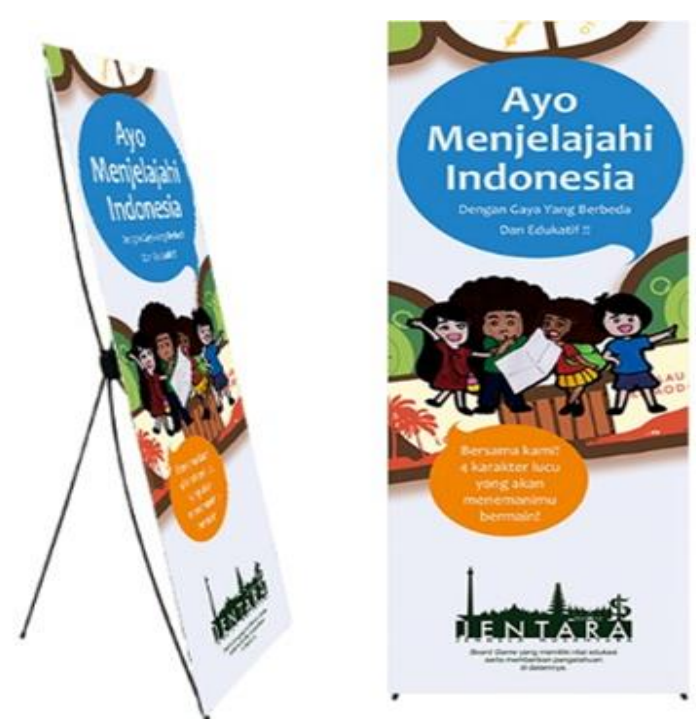

Gambar 15. Desain akhir banner JENTARA

Sumber: Dokumentasi penulis

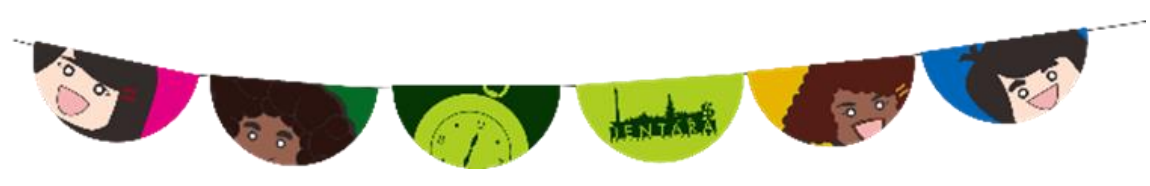

Gambar 16. Desain akhir flag chain JENTARA

Sumber: Dokumentasi penulis
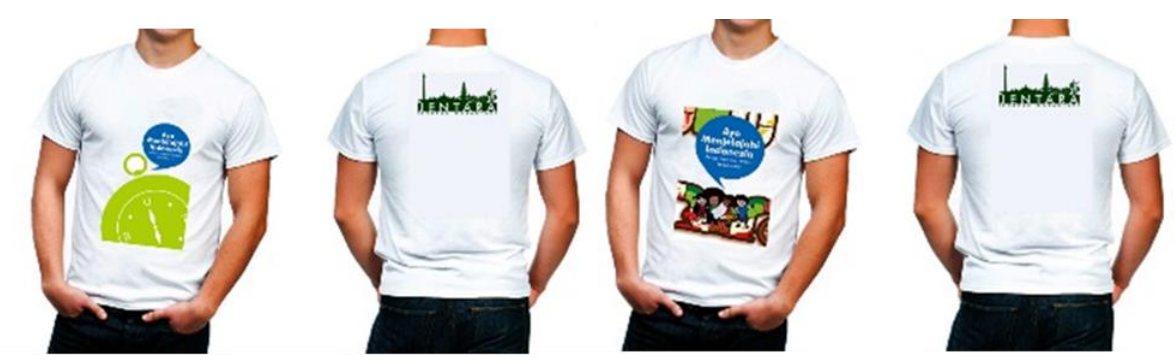

Gambar 17. Desain akhir kaos JENTARA

Sumber: Dokumentasi penulis

\section{SIMPULAN DAN SARAN}

\section{Kesimpulan}

Dalam merancang sebuah papan permainan dibutuhkan waktu, ketekunan, disiplin, ketelitian, serta kerja keras untuk dapat menghasilkan sebuah permainan yang layak dimainkan oleh keluarga. Perancangan tersebut haruslah memiliki karakteristik dan keunikan tersendiri agar board game JENTARA dapat dibedakan dengan board game lainnya serta mudah dikenali dan diingat oleh masyarakat. 
Media utama yang penulis rancang pada perancangan ini terdiri dari papan permainan, pion/bidak, kartu, buku panduan, logo, kemasan dan tempat kartu. Walaupun semua media utama tersebut memiliki fungsi yang berbeda, namun mereka saling terikat satu sama lain. Hal ini disebabkan karena pada sebuah permainan papan diperlukan banyak media utama untuk mendukung permainan tersebut. Selain itu penulis juga merancang media-media lain sebagai media pendukung yang digunakan untuk melengkapi dan mengenal lebih baik perancangan JENTARA. Media-media pendukung tersebut dirancang dengan menggunakan desain yang ada pada perancangan board game JENTARA, agar media-media tersebut dapat ikut mewakili karakteristik dan keunikan desain JENTARA namun tetap informatif dan komunikatif.

\section{Saran}

Setelah melewati proses Perancangan Board Game Edukatif untuk Keluarga, penulis dapat memberikan saran bagi orang-orang yang akan melakukan perancangan, sebagai berikut: 1) Untuk menghasilkan sebuah karya yang baik diperlukan adanya konsep perancangan yang baik sebagai dasarnya, selain itu perancang harus memiliki pengetahuan mendalam terhadap objek maupun subjek yang dirancang serta teori-teori desain komunikasi visual yang digunakan dalam perancangan; 2) Dalam melakukan perancangan sebuah board game edukatif, perancang hendaklah meneliti lebih dalam permainan seperti apa yang akan dihasilkan dan apa saja tujuan yang akan dibuat pada perancangan tersebut. Perancang harus bisa memanfaatkan waktu dengan sebaik mungkin dan tekun dalam mengerjakan sebuah karya agar mendapatkan hasil yang baik dan memuaskan.

\section{DAFTAR PUSTAKA}

Ismail, Andang. (2006). Education Games, Menjadi cerdas dan ceria dengan Permainan Edukatif. Yogyakarta: Pilar Media.

Kusantanti, D. (2004). Metode Pengajaran di Taman Kanak-Kanak. Jakarta: Rineka Cipta.

Mubarak, Abdul. (2013). Pahlawan Kemerdekaan (Permainan Board Game Ksatria Mahardhika). Undergraduate Theses Program Studi Desain Grafis.

Mulyadi, Seto. (2004). Bermain dan Kreativitas (Upaya Mengembangkan Krativitas Anak Melalui Kegiatan Bermain). Jakarta: Papas Sinar Sinanti. 